\title{
Subclinical Hearing Loss, Longer Sleep Duration, and Cardiometabolic Risk Factors in Japanese General Population
}

\author{
Kei Nakajima, ${ }^{1}$ Eiichiro Kanda, ${ }^{2}$ Ami Hosobuchi, ${ }^{1}$ and Kaname Suwa ${ }^{3}$ \\ ${ }^{1}$ Division of Clinical Nutrition, Department of Medical Dietetics, Faculty of Pharmaceutical Sciences, Josai University, \\ 1-1 Keyakidai, Sakado, Saitama 350-0295, Japan \\ ${ }^{2}$ Department of Nephrology, Tokyo Kyosai Hospital, Nakameguro 2-3-8, Meguroku, Tokyo 153-8934, Japan \\ ${ }^{3}$ Saitama Health Promotion Corporation, 519 Kamiookubo, Saitama, Saitama 338-0824, Japan \\ Correspondence should be addressed to Kei Nakajima; keinaka@josai.ac.jp
}

Received 30 May 2014; Revised 6 July 2014; Accepted 20 July 2014; Published 12 August 2014

Academic Editor: Myer III Myer

Copyright (C) 2014 Kei Nakajima et al. This is an open access article distributed under the Creative Commons Attribution License, which permits unrestricted use, distribution, and reproduction in any medium, provided the original work is properly cited.

Hearing loss leads to impaired social functioning and quality of life. Hearing loss is also associated with sleeping disorders and cardiometabolic risk factors. Here, we determined whether subclinical hearing loss is associated with sleep duration and cardiometabolic risk factors in a cross-sectional and longitudinal study of healthy Japanese general population. 48,091 men and women aged 20-79 years who underwent medical checkups were included in a cross-sectional study, and 6,674 were included in an 8-year longitudinal study. The prevalence of audiometrically determined hearing loss ( $>25 \mathrm{~dB})$ at 4000 and $1000 \mathrm{~Hz}$ increased significantly with increasing sleep duration in any age strata. Logistic regression analysis showed that compared with reference sleep duration $(6 \mathrm{~h})$ longer sleep duration $(\geq 8 \mathrm{~h})$ was significantly associated with hearing loss, even after adjusting for potential confounding factors. Simultaneously, hearing loss was significantly associated with male sex, diabetes, and no habitual exercise. In the longitudinal study, the risk of longer sleep duration $(\geq 8 \mathrm{~h})$ after 8 years was significantly greater in subjects with hearing loss at $4000 \mathrm{~Hz}$ at baseline. In conclusion, current results suggest a potential association of subclinical hearing loss with longer sleep duration and cardiometabolic risk factors in a Japanese general population.

\section{Introduction}

The progressive aging of society is leading to an increase in the prevalence of hearing loss worldwide. Although hearing loss is not directly life threatening, it may impair social functioning and quality of life, causing isolation, frustration, and impaired communication [1-6]. Meanwhile, several studies have revealed that sleeping disorders such as insomnia and daytime sleepiness are associated with hearing impairments, including hearing loss and tinnitus [7-10]. Therefore, some factors associated with sleep may be associated with hearing loss. To date, however, no study has examined the putative association between hearing loss and sleep duration.

In this context, we focused on subclinical objective hearing loss, which is often undetected and left untreated $[4,6]$, and investigated the lifestyles of individuals with subclinical hearing loss and the etiology of subclinical hearing loss. Because frequency of 500 to $4000 \mathrm{~Hz}$ is important range for speech processing [6], we determined whether hearing function at representative high $(4000 \mathrm{~Hz})$ and low $(1000 \mathrm{~Hz})$ frequencies, which are usually examined in a hearing screening test in Japan [11-13], was associated with lifestyle factors, including sleep duration per night and cardiometabolic risk factors, in a cross-sectional study of Japanese general population.

Because hearing loss has been shown to be associated with cardiometabolic risk factors, such as diabetes and smoking [11-16], we considered these factors as relevant confounding factors and also examined the associations between hearing loss and these cardiometabolic risk factors. To examine the effects of subclinical hearing loss on the incidence of longer sleep duration ( $8 \mathrm{~h}$ and $\geq 9 \mathrm{~h}$ ), we performed a retrospective 8 year longitudinal study in an independent group of subjects whose sleep duration was classified as normal or short $(\leq 7 \mathrm{~h})$ at baseline. 


\section{Methods}

2.1. Study Design. This study was based on a composite research program that is being conducted to identify the factors associated with cardiometabolic and atherosclerotic diseases. The design of this study is described in more detail elsewhere [17]. This retrospective study consists of data recorded during annual medical checkups of asymptomatic individuals living or working in Saitama Prefecture, a suburb of Tokyo, Japan. The study started in 2011 and involves the collaboration of three institutions in Saitama: Jichi Medical University, Josai University, and Saitama Health Promotion Corporation. The protocol, which conforms to the Declaration of Helsinki, was approved by the Ethics Committee of Jichi Medical University and Josai University and by the Committee of the Saitama Health Promotion Corporation. Written informed consent was obtained from all participants. Since 1997, Saitama Health Promotion Corporation, a public interest corporation, has supported the health of individuals, including children and adolescents, living or working in Saitama Prefecture, primarily by carrying out various types of medical checkups [18].

\subsection{Subjects}

2.2.1. Cross-Sectional Study. We digitally stored data from 83 286 apparently healthy subjects aged 20-79 years old who underwent medical checkups at Saitama Health Promotion Corporation between April 1, 2007, and March 31, 2008. Subjects with diagnosed or undiagnosed self-reported hearing loss $(n=488)$ were excluded from the analysis because the cause and treatment received (e.g., hearing aids and pharmacotherapy) were not available in this study. Subjects with self-reported depression and sleep apnea syndrome were also excluded because these conditions may affect sleep duration [19-22]. The exclusion criteria applied in this study and the disposition of subjects are shown in Figure 1. Subjects with self-reported tinnitus $(n=1,396)$ were included because tinnitus was usually mild and was not always diagnosed by a physician in this study. Consequently, 48091 subjects were included in the cross-sectional study.

2.2.2. Longitudinal Study. When we selected subjects for the longitudinal study from those included in the cross-sectional study, the number of subjects whose baseline sleep duration was normal or short $(\leq 7 \mathrm{~h})$ and who underwent the same checkup four times between April 1, 1999, and March 31, 2008 ( 8 years duration), was $<1,000$. Therefore, subjects included in the longitudinal study were identified from the original study population, which means the subjects included in the longitudinal study differed from those included in the crosssectional study. However, the assessment of hearing loss and other laboratory tests were identical between the crosssectional and longitudinal studies. After excluding subjects with incomplete data and those with known ear diseases, 6,774 subjects with normal or short sleep duration at baseline were included in the longitudinal study (Figure 1). During 8 years, many subjects abandoned the medical checkup held by Saitama Health Promotion Corporation (average proportions of not undergoing the same checkup next year was approximately one-fourth to one-third during 1999 2008) and changed to other checkups because of house moving, resignation, or change of jobs, child care, or family reasons, resulting in the decreased number of subjects in the longitudinal study.

2.2.3. Anthropometric, Laboratory, and Audiometric Tests. Anthropometric, laboratory, and audiometric tests were carried out in the morning. Serum parameters were measured using standard methods on Hitachi autoanalyzers (Tokyo, Japan) at Saitama Health Promotion Corporation. Hemoglobin ( $\mathrm{Hb}$ ) Alc was converted to national glycohemoglobin standardization program levels using a validated formula [23]. Unfortunately, fasting plasma glucose levels were not available in both studies. The hearing test was conducted in a quiet room by trained staff using an ordinary audiometer. Subclinical (objective) hearing loss was defined as a puretone average hearing loss of $>25 \mathrm{~dB}$ at high $(4000 \mathrm{~Hz})$ and low $(1000 \mathrm{~Hz})$ frequencies.

2.2.4. Sleep Duration and Confounding Factors. Self-reported sleep duration per night, which was obtained as a response to the simple question about sleep, was divided into five categories $(\leq 5,6,7,8$, and $\geq 9 \mathrm{~h})$ according to previous studies $[24,25]$. The duration of daytime nap was not taken into consideration in this study. Subjects completed a form to record history of cardiovascular disease (including stroke), complications (hypertension, diabetes, or dyslipidemia), alcohol consumption (no, occasional, 1-3 times/week, 46 times/week, or daily), smoking status (no, past, or current), regular exercise ( $\geq 30 \mathrm{~min}$ per time; no, occasional, once/week, or at least twice/week), and work duration $(\leq 6$, $7,8,9,10$, or $\geq 11 \mathrm{~h}$ ). The influence of body weight was evaluated in terms of body mass index (BMI), which was divided into six categories $(\leq 18.9,19.0-20.9,21.0-22.9,23.0-$ $24.9,25.0-26.9$, and $\geq 27.0 \mathrm{~kg} / \mathrm{m}^{2}$ ). We took into consideration that WHO has proposed that BMI cutoff points for overweight and obesity for Asian populations should be lower ( $\geq 23.0 \mathrm{~kg} / \mathrm{m}^{2}$ and $\geq 27.5 \mathrm{~kg} / \mathrm{m}^{2}$, resp.) compared to Western populations [26]. Since the proportions of subjects classified as underweight (i.e., $<18.5 \mathrm{~kg} / \mathrm{m}^{2}$ ) or obese (i.e., $\geq 30.0 \mathrm{~kg} / \mathrm{m}^{2}$ ) are very low $(4.8 \%$ and $5.0 \%$, resp.) in this study, we round up the low and high BMI cutoffs to 19 and $27 \mathrm{~kg} / \mathrm{m}^{2}(7.4 \%$ and $15.1 \%$, resp.). The influence of systemic inflammation was roughly evaluated in terms of the circulating white blood cell count, a putative risk factor for cardiovascular disease [27-29], which was divided into quartiles. Because organic solvents can affect sleep duration [30, 31], the use of organic solvent in the workplace was taken into account, although the type was not recorded and the number of subjects was limited $(n=39,691)$.

2.2.5. Statistical Analysis. Data are expressed as means (SD) or medians (interquartile range). Differences in clinical parameters and categorical variables between the five categories of sleep duration were examined by one-way analysis of variance (ANOVA) and $\chi^{2}$ tests, respectively. The prevalence 
Exclusion criteria of subjects and flow chart

83286 apparently healthy subjects aged 20-79 years old who underwent a medical checkup from April 1, 2007, to March 31, 2008

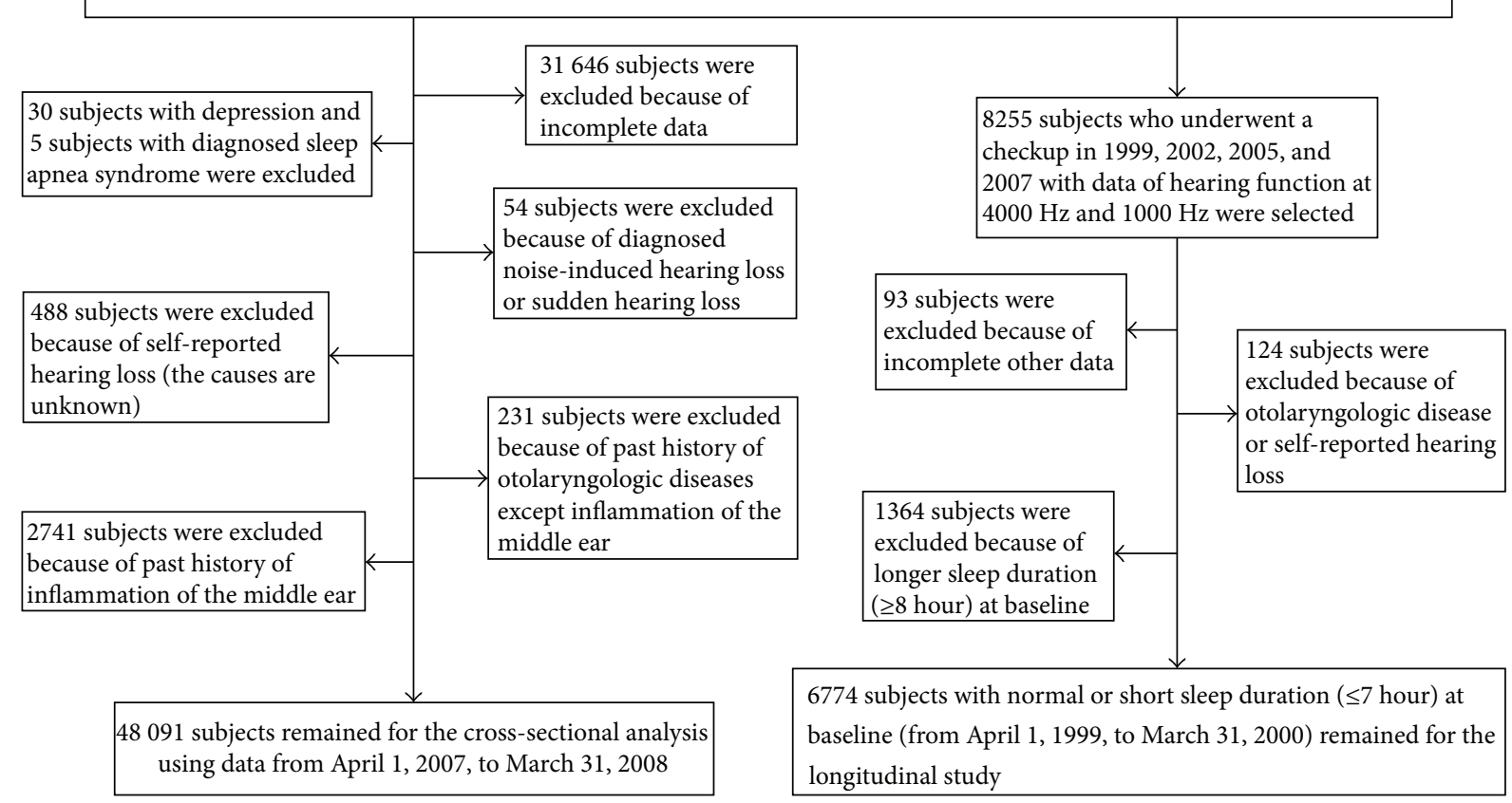

FIGURE 1: Exclusion criteria and subject disposition.

of hearing loss was first evaluated in four age groups (20$39,40-49,50-51$, and $60-79$ years) because advancing age is one of the main risk factors for hearing loss. In the cross-sectional study, multivariate logistic regression models were used to examine whether subclinical hearing loss was associated with lifestyle and cardiometabolic risk factors to calculate odds ratios (OR) and 95\% confidence intervals (CI) with adjustment for relevant confounders. After sleep durations in five categories of sleep duration were coded as $5,6,7,8$, and 9 for $\leq 5 \mathrm{~h}, 6 \mathrm{~h}, 7 \mathrm{~h}, 8 \mathrm{~h}$, and $\geq 9 \mathrm{~h}$, respectively, associations between sleep duration as a continuous variable and hearing loss were examined. The associations between relevant confounders and hearing loss were also evaluated.

For the longitudinal analysis, multivariate logistic regression models were also used to examine the association between baseline hearing loss and risk of longer sleep duration $(8 \mathrm{~h}$ and $\geq 9 \mathrm{~h}$ ) after 9 years to calculate relative risk (RR) and 95\% confidence interval (CI) because the incidence of longer sleep duration after 9 years was $<10 \%$ and the ORs are expressed as relative risks in the longitudinal study [32]. In this analysis, the provisional reference BMI categories were defined as a BMI of $21.0-22.9 \mathrm{~kg} / \mathrm{m}^{2}$ based on the proposal by the World Health Organization regarding overweight and obese classifications for Asian populations [26]. Statistical analyses were performed using IBM-SPSS version 18.0 (PASW statistics 18; Chicago, IL, USA) and Statview version 5.0 (SAS Institute; Cary, NC, USA). Values of $P<0.05$ were considered statistically significant.

\section{Results}

3.1. Cross-Sectional Study. The clinical characteristics of the subjects are presented in Table 1. Subjects with longer sleep duration were more frequently men, were older, and had a shorter work duration, with increased numbers of cardiometabolic risk factors (especially decreased high-density lipoprotein cholesterol). BMI, white blood cell count, and the frequency of current smokers, no regular exercise, or use of organic solvents at work showed U- or J-shaped relationships with sleep duration. The prevalence of cardiovascular disease, hypertension, and diabetes increased with increasing sleep duration. Similarly, the prevalence of hearing loss increased with increasing sleep duration, irrespective of the left or right ear, or frequency. The proportions of manufacturing and construction workers were higher in the longer sleep duration groups ( $8 \mathrm{~h}$ and $\geq 9 \mathrm{~h}$ ), whereas the opposite was true for the proportions of clerical, technical, and medical workers.

Figure 2 shows the prevalence of hearing loss according to age groups. The prevalence of hearing loss at $4000 \mathrm{~Hz}$ increased significantly with increasing sleep duration in any age strata except for younger age (20-39 years old). Likewise, the prevalence of hearing loss at $1000 \mathrm{~Hz}$ increased significantly with increasing sleep duration, particularly in the older age groups. However, there seemed to be a slight J-shaped relationship in subjects aged 60-79 years.

Multivariate logistic regression analyses showed that, compared with sleep duration of $\leq 5 \mathrm{~h}$, the other categories of 
TABLE 1: Clinical characteristics of subjects according to the five sleep duration categories.

\begin{tabular}{|c|c|c|c|c|c|c|}
\hline Five categories by sleep duration & Total & $\leq 5 \mathrm{~h}$ & $6 \mathrm{~h}$ & $7 \mathrm{~h}$ & $8 \mathrm{~h}$ & $\geq 9 \mathrm{~h}$ \\
\hline$N,(\%$ of total $)$ & 48,091 & $5,049(10.5)$ & $22,386(46.5)$ & $15,106(31.4)$ & $5,176(10.8)$ & $374(0.8)$ \\
\hline Age, years & $42.3(12.1)$ & $39.7(11.2)$ & $41.0(11.7)$ & $43.4(12.3)$ & $46.3(12.8)$ & $49.1(15.5)$ \\
\hline Men, $n(\%)$ & $33,026(68.7)$ & $3,208(63.5)$ & $14,793(66.1)$ & $10,767(71.3)$ & $3,965(76.6)$ & $293(78.3)$ \\
\hline BMI, $\mathrm{kg} / \mathrm{m}^{2}$ & $23.5(3.6)$ & $23.7(3.9)$ & $23.5(3.7)$ & $23.4(3.4)$ & $23.5(3.5)$ & $23.6(3.5)$ \\
\hline Systolic blood pressure, mmHg & $123(17.3)$ & $121(16.7)$ & $122(16.9)$ & $124(17.5)$ & $127(18.4)$ & $128(18.5)$ \\
\hline Diastolic blood pressure, $\mathrm{mmHg}$ & $75(13.3)$ & $74(13.5)$ & $74(13.1)$ & $75(13.5)$ & $77(13.3)$ & $77(13.7)$ \\
\hline Total cholesterol, mg/dL & $199(35.5)$ & $198(35.7)$ & $199(35.5)$ & $199(35.2)$ & $201(35.7)$ & $198(38.8)$ \\
\hline Triglyceride, mg/dL & $96(64-153)$ & $88(59-146)$ & $93(62-148)$ & $100(67-157)$ & $107(70-170)$ & $103(73-169)$ \\
\hline HDL cholesterol, mg/dL & $61.4(15.5)$ & $61.9(15.6)$ & $61.5(15.6)$ & $61.2(15.4)$ & $61.1(15.9)$ & $59.0(15.1)$ \\
\hline HbAlc, \%, NGSP & $5.5(0.7)$ & $5.5(0.8)$ & $5.5(0.7)$ & $5.5(0.7)$ & $5.6(0.8)$ & $5.7(1.1)$ \\
\hline White blood cell, $\times 10^{2} / \mu \mathrm{L}$ & $65.2(17.6)$ & $66.5(18.5)$ & $64.8(17.4)$ & $65.0(17.6)$ & $66.3(18.1)$ & $67.3(19.4)$ \\
\hline Past history of CVD, $n(\%)$ & $711(1.5)$ & $72(1.4)$ & $301(1.3)$ & $229(1.5)$ & $100(1.9)$ & $9(2.4)$ \\
\hline \multicolumn{7}{|l|}{ Complication } \\
\hline Hypertension, $n(\%)$ & $3,697(7.7)$ & $264(5.2)$ & $1,436(6.4)$ & $1,325(8.8)$ & $623(12.0)$ & $49(13.1)$ \\
\hline Dyslipidemia, $n(\%)$ & $2,187(4.5)$ & $164(3.2)$ & $969(4.3)$ & $756(5.0)$ & $280(5.4)$ & $18(4.8)$ \\
\hline Diabetes, $n(\%)$ & $1,402(2.9)$ & $106(2.1)$ & $580(2.6)$ & $477(3.2)$ & $217(4.2)$ & $22(5.9)$ \\
\hline Subjects with high HbAlc ( $\geq 6.5 \%), n(\%)$ & $2,521(5.2)$ & $217(4.3)$ & $1,019(4.6)$ & $851(5.6)$ & $397(7.7)$ & $37(9.9)$ \\
\hline \multicolumn{7}{|l|}{ Alcohol consumption } \\
\hline 1 3/w/4 6/w/daily (\%) & $16.7 / 11.6 / 16.9$ & $17.9 / 8.1 / 12.6$ & $17.7 / 10.9 / 13.7$ & $15.9 / 13.1 / 19.7$ & $14.3 / 13.9 / 26.4$ & $11.0 / 8.8 / 30.2$ \\
\hline \multicolumn{7}{|l|}{ Smoker } \\
\hline Past/current (\%) & $11.2 / 38.1$ & $6.8 / 40.5$ & $10.4 / 36.9$ & $12.9 / 37.6$ & $13.8 / 41.7$ & $10.7 / 44.7$ \\
\hline \multicolumn{7}{|l|}{ Having regular exercise } \\
\hline No/occasional $\sim 1 / \mathrm{w} / \geq 2 / \mathrm{w}(\%)^{*}$ & $51.0 / 31.8 / 17.2$ & $57.4 / 28.4 / 14.3$ & $51.4 / 32.2 / 16.4$ & $48.4 / 33.2 / 18.4$ & $49.9 / 30.2 / 20.0$ & $57.0 / 24.9 / 18.2$ \\
\hline Self-reported tinnitus, $n(\%)$ & $1,396(2.9)$ & $121(2.4)$ & $635(2.8)$ & $457(3.0)$ & $170(3.3)$ & $13(3.5)$ \\
\hline Hearing loss at $4,000 \mathrm{~Hz}$ in the left ear, $n(\%)$ & $3,068(6.4)$ & $188(3.7)$ & $1,013(4.5)$ & $1,100(7.3)$ & $675(13.0)$ & $92(24.6)$ \\
\hline Hearing loss at $4,000 \mathrm{~Hz}$ in the right ear, $n(\%)$ & $2,883(6.0)$ & $158(3.1)$ & $952(4.3)$ & $1,012(6.7)$ & $656(12.7)$ & $105(28.1)$ \\
\hline Hearing loss at $1,000 \mathrm{~Hz}$ in the left ear, $n(\%)$ & $1,097(2.3)$ & $90(1.8)$ & $404(1.8)$ & $367(2.4)$ & $192(3.7)$ & $44(11.8)$ \\
\hline Hearing loss at $1,000 \mathrm{~Hz}$ in the right ear, $n(\%)$ & $1,070(2.2)$ & $81(1.6)$ & $390(1.7)$ & $338(2.2)$ & $225(4.3)$ & $36(9.6)$ \\
\hline Work duration, hour & $8.6(1.4)$ & $9.2(1.6)$ & $8.7(1.4)$ & $8.4(1.3)$ & $8.3(1.3)$ & $8.1(1.5)$ \\
\hline \multicolumn{7}{|l|}{ Occupation, $(\%)^{*}$} \\
\hline Clerical workers & 21.2 & 17.5 & 22.4 & 22.5 & 17.0 & 7.2 \\
\hline Production workers & 8.3 & 6.7 & 7.4 & 9.4 & 9.9 & 12.8 \\
\hline Service workers & 10.6 & 11.7 & 10.8 & 9.8 & 10.2 & 15.8 \\
\hline Managerial workers & 6.8 & 5.9 & 6.5 & 7.7 & 6.9 & 2.9 \\
\hline Technical workers & 5.2 & 6.6 & 5.4 & 4.8 & 4.2 & 2.7 \\
\hline Construction workers & 6.6 & 5.7 & 5.4 & 6.6 & 12.2 & 20.3 \\
\hline Medical workers & 4.4 & 4.9 & 4.6 & 4.2 & 3.9 & 2.9 \\
\hline Transport workers & 3.1 & 6.8 & 2.7 & 2.2 & 3.4 & 6.2 \\
\hline Workers not classifiable or nonemployed & 33.8 & 34.1 & 34.8 & 32.9 & 32.4 & 29.1 \\
\hline $\begin{array}{l}\text { Organic solvent workers, } n(\%) \\
\text { (total available } n=39,691 \text { ) }\end{array}$ & $1,053(2.7)$ & $109(2.6)$ & $427(2.3)$ & $371(3.0)$ & $134(3.2)$ & $12(4.0)$ \\
\hline
\end{tabular}

The data are expressed as means (SD). Triglyceride is expressed as medians (interquartiles).

${ }^{*}$ Total sum is not $100 \%$ in some cases because of round-off to two decimal places.

Differences in parameters and categorical values between five sleep duration categories were significant (analysis of variance/ $\chi^{2}$ test; past history of CVD, and medical workers, both $P=0.01$ and all others, $P<0.001)$, except self-reported tinnitus $(P=0.06)$.

BMI: body mass index, HDL: high-density lipoprotein, NGSP: national glycohemoglobin standardization program, CVD: cardiovascular disease (including stroke). 


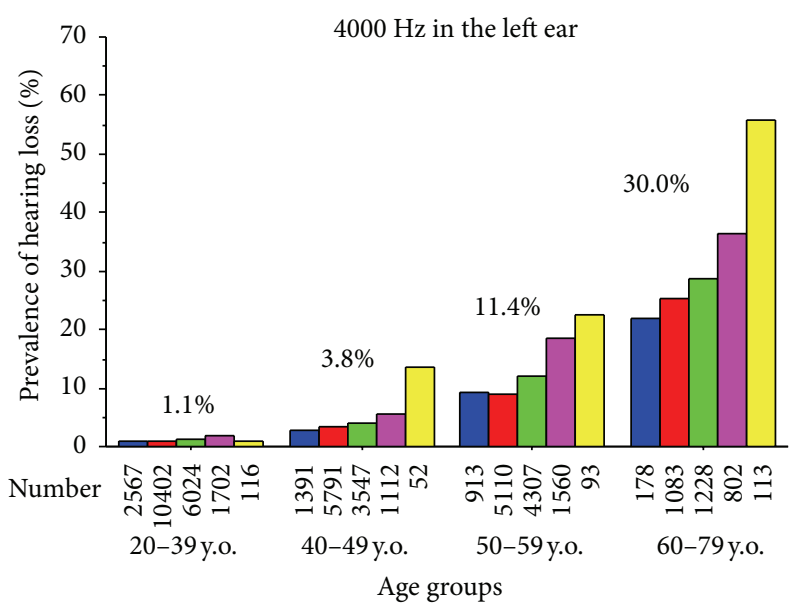

(a)

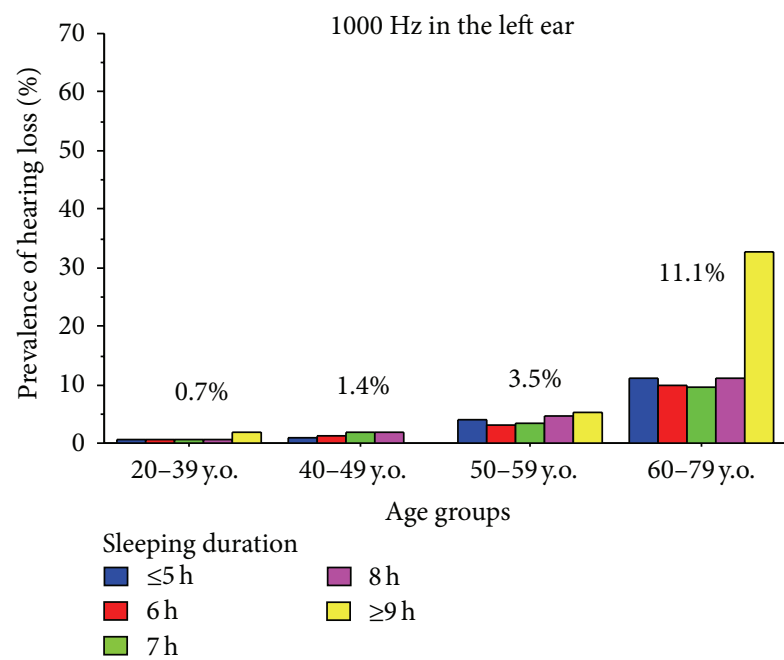

(c)

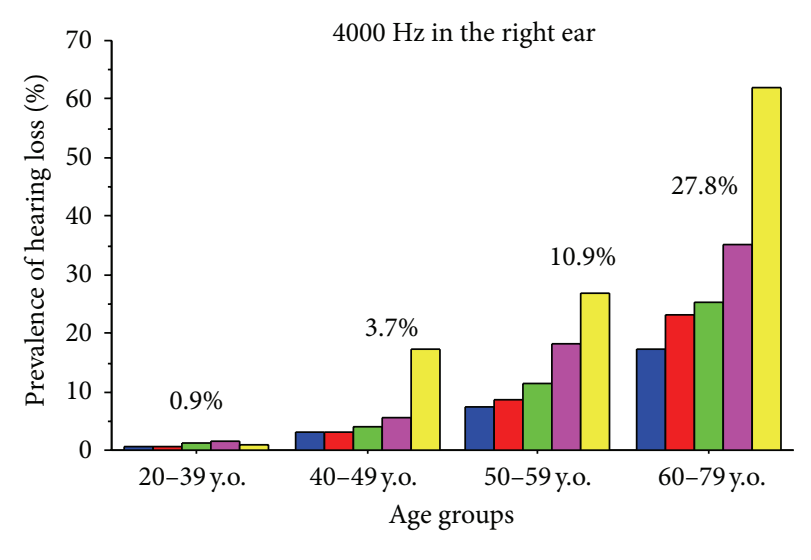

(b)

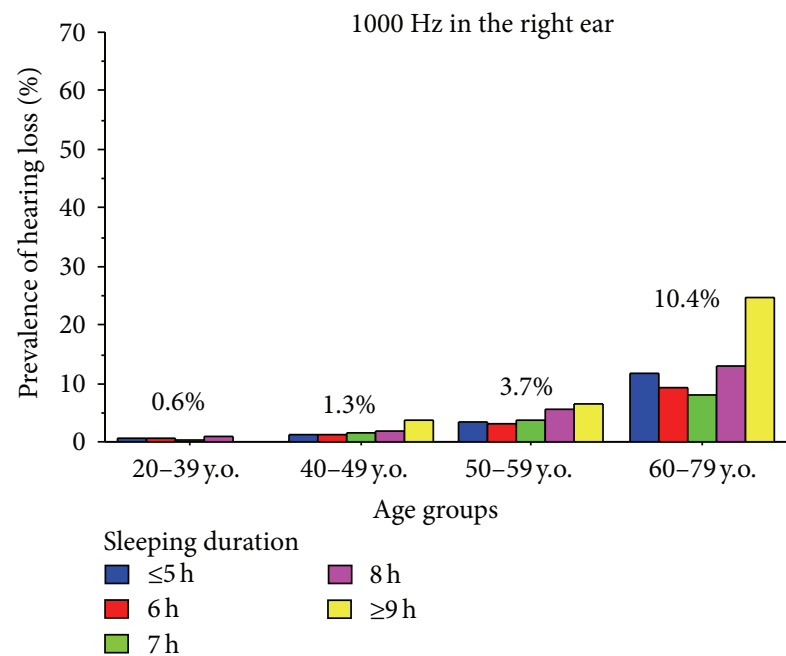

(d)

Figure 2: Prevalence of hearing loss according to age group. The number of subjects is shown under the column for hearing loss at $4000 \mathrm{~Hz}$ in the left ear (top-left panel). The numbers of subjects included in the other panels were identical. The percentage (\%) above the column expresses the average of prevalence of hearing loss according to the age group. The prevalence of hearing loss at $4000 \mathrm{~Hz}$, but not at $1000 \mathrm{~Hz}$, increased significantly with increasing sleep duration in most age groups ( $\chi^{2}$ test). Left ear at $4000 \mathrm{~Hz}$ : 20-39 years, $P=0.002$; all other age groups, $P<0.001$. Right ear at $4000 \mathrm{~Hz}$ : all age groups, $P<0.001$. Left ear at $1000 \mathrm{~Hz}$ : $20-39$ years, $P=0.51 ; 40-49$ years, $P=0.20 ; 50-59$ years, $P=0.08 ; 60-79$ years, $P<0.001$. Right ear at $1000 \mathrm{~Hz}$ : $20-39$ years, $P=0.34 ; 40-49$ years, $P=0.13 ; 50-59$ years, $P<0.001 ; 60-79$ years, $P<0.001$. y.o.: years old.

sleep duration were significantly associated with hearing loss at 4000 and $1000 \mathrm{~Hz}$ at least in one ear (Table 2). Adjustment for confounding factors, including age and sex, markedly attenuated the associations, but changing the reference sleep duration category from $\leq 5 \mathrm{~h}$ to $6 \mathrm{~h}$ (Model $2 \mathrm{~b}$ ) or additional adjustment for the use of organic solvents at work (Model 3) did not. Likewise, sleep duration as a continuous variable was also significantly associated with hearing loss at 4000 and $1000 \mathrm{~Hz}$.

Table 3 shows the ORs for the confounding factors, except age, for hearing loss. Male sex, diabetes, no regular exercise, and tinnitus were significantly associated with hearing loss at both frequencies, whereas regular alcohol consumption, but not daily alcohol consumption, was inversely associated with hearing loss. Low body weight, the highest quartile of white blood cell count $\left(\geq 88.9 \times 10^{2} / \mu \mathrm{L}\right)$, current smoking, and daily alcohol consumption were significantly associated with hearing loss at $4000 \mathrm{~Hz}$. Work duration was significantly and inversely associated with hearing loss at $1000 \mathrm{~Hz}$ but not at $4000 \mathrm{~Hz}$. Compared with clerical work, other work types, except managerial and medical work, were significantly associated with hearing loss at $4000 \mathrm{~Hz}$ (ORs 1.24-4.49) and $1000 \mathrm{~Hz}$ (ORs 1.34-1.90), even after controlling for confounding factors, including work duration (data not shown).

3.2. Longitudinal Study. The baseline clinical characteristics of subjects included in the longitudinal study (Table 4) are similar to those of the subjects included in the cross-sectional study (Table 1). Table 5 shows RRs of hearing loss at baseline for the longer sleep duration ( $\geq 8 \mathrm{hr}$ ) after 9 years. The risk of 
TABLE 2: Odds ratios of each sleep duration for hearing loss.

\begin{tabular}{ccccccc}
\hline Frequency & Sleep durations & $\leq 5 \mathrm{~h}$ & $6 \mathrm{~h}$ & $7 \mathrm{~h}$ & $8 \mathrm{~h}$ & \\
\hline $4,000 \mathrm{~Hz}$ & & & & & & \\
Model 1 & & 1 & $1.27(1.10-1.46)^{\ddagger}$ & $2.06(1.79-2.36)^{\ddagger}$ & $3.92(3.39-4.54)^{\ddagger}$ & $8.38(6.50-10.8)^{\ddagger}$ \\
Model 2 & $\mathrm{a}$ & 1 & $1.04(0.90-1.21)$ & $1.17(1.01-1.37)^{*}$ & $1.38(1.17-1.64)^{\ddagger}$ & $1.82(1.32-2.50)^{\ddagger}$ \\
Model 3 & $\mathrm{b}$ & $0.98(0.84-1.14)$ & 1 & $1.11(1.01-1.21)^{*}$ & $1.30(1.16-1.45)^{\ddagger}$ & $1.72(1.28-2.31)^{\ddagger}$ \\
$1,000 \mathrm{~Hz}$ & & 1 & $1.07(0.90-1.27)$ & $1.20(1.01-1.43)^{*}$ & $1.36(1.13-1.64)^{\dagger}$ & $1.75(1.22-2.50)^{\dagger}$ \\
Model 1 & & & & & & \\
Model 2 & $\mathrm{a}$ & 1 & $1.08(0.89-1.31)$ & $1.42(1.17-1.73)^{\ddagger}$ & $2.41(1.96-2.97)^{\ddagger}$ & $6.80(4.88-9.48)^{\ddagger}$ \\
Model 3 & $\mathrm{b}$ & $1.07(0.88-1.31)$ & $0.93(0.77-1.14)$ & $0.95(0.77-1.16)$ & $1.13(0.90-1.41)$ & $2.06(1.43-2.97)^{\ddagger}$ \\
\hline
\end{tabular}

${ }^{*} P<0.05,{ }^{\dagger} P<0.01$, and ${ }^{\ddagger} P<0.001$.

The number of subjects in each group is the same as that in Table 1.

Hearing loss was defined as $>25 \mathrm{~dB}$ hearing level in the right and/or left sides of ear.

Model 1: unadjusted.

Model 2: adjusted for age, sex, smoking, alcohol consumption, and having regular exercise, quartile of white blood cell counts, six tiles of body mass index, and past history of cardiovascular disease, complications (hypertension, dyslipidemia, and diabetes), self-reported tinnitus, working duration, and occupation. The reference sleep duration was $\leq 5 \mathrm{~h}$ in Model 2a and $6 \mathrm{~h}$ in Model $2 \mathrm{~b}$.

Model 3: Model 2a plus adjustments for organic solvent work (available $n=39,691$ ).

long sleep duration was significantly greater in subjects with hearing loss at $4000 \mathrm{~Hz}$ at baseline compared with subjects without such hearing loss. This increased risk remained significant after adjusting for potential confounding factors at baseline. Although subjects with hearing loss at $1000 \mathrm{~Hz}$ at baseline had a significantly higher risk for longer sleep duration, this disappeared after adjusting for fundamental confounding factors (Model 2).

\section{Discussion}

Our cross-sectional and longitudinal studies provide robust evidence that subclinical hearing loss, especially at high frequencies, is associated with longer sleep duration, which was particularly depicted in older age, independently of relevant lifestyle factors, cardiometabolic risk factors, and the use of organic solvents at work. These associations were not weakened when the reference sleep duration was changed to $6 \mathrm{~h}$, the major sleep duration category in this study. Although several epidemiological studies have shown U- or J-shaped relationships between sleep duration and clinical disorders, such as obesity and diabetes $[24,33,34]$, the relationship between hearing loss at $4000 \mathrm{~Hz}$ and sleep duration in our study was nearly linear in all of the age categories. Because many studies have shown that noise-induced hearing loss, a major form of acquired hearing loss [35], gradually begins around the frequency of $4000 \mathrm{~Hz}[36,37]$, currently observed hearing loss might be attributable to a great extent to the longterm noise exposure, which was not measured in this study.

Regarding the cause-effect relationship, considering the results of our longitudinal study, it is likely that longer sleep duration may occur because of or in conjunction with hearing loss. In other words, subclinical hearing loss may be a predictor of long sleep duration, which may be related to the development of cardiometabolic disease [24, 33-38]. Hearing loss is also associated with dementia and cognitive impairment [39-42], whereas cognitive impairments, including Alzheimer disease, are associated with sleep and circadian problems [43-45]. Therefore, it is possible that long sleep duration might reflect other clinical conditions that were not examined in this study and that the currently observed associations may be spurious and unknown factors might mediate two conditions. Frustration and uneasiness associated with hearing loss or noisy daytime environments may reduce sleep quality and provoke insomnia $[9,10,46]$ and may result in longer sleep durations. By contrast, once individuals with hearing loss do fall asleep, they could maintain good sleep without waking during the night. Hearing loss might also protect sleep by reducing the subjects' awareness of environmental noise during sleep [8] and might prolong sleep duration [46-48].

Meanwhile, many previous studies have provided evidence that diabetes, cardiometabolic disease, and smoking are associated with hearing loss [11-16], plausibly through diabetic micro- and macroangiopathy $[14,49,50]$. Thus, like typical diabetic complications, hearing loss may be one of complications following diabetic or atherosclerotic etiologies. Nevertheless, there is also a possibility that long-time sleep in turn may deteriorate the pathophysiology of diabetes and atherosclerosis because of putative associations between long-time sleep and diabetes [24, 33-38]. Intriguingly, low BMI (i.e., low body weight rather than obesity) was associated with hearing loss at $4000 \mathrm{~Hz}$. Underweight might be associated with increased risk for hearing loss through inadequate intake of dietary nutrients, especially vitamin $\mathrm{B}_{12}$ and antioxidants [51-55], or other factors that were previously reported to be associated with increased mortality in underweight people [56-58]. In our study, hearing loss at $4000 \mathrm{~Hz}$ was also associated with current smoking, daily alcohol consumption, and high white blood cell count, which are all generally classified as cardiovascular risk factors [2729, 59-62]. Recently, Ronksley et al. [60] have shown that 
TABLE 3: Odds ratio of cardiovascular risk factors for hearing loss.

\begin{tabular}{|c|c|c|c|c|}
\hline \multirow{2}{*}{ Models } & \multicolumn{2}{|c|}{$4,000 \mathrm{~Hz}$} & \multicolumn{2}{|c|}{$1,000 \mathrm{~Hz}$} \\
\hline & Unadjusted & Multivariate adjusted & Unadjusted & Multivariate adjusted \\
\hline \multicolumn{5}{|l|}{ Gender } \\
\hline Men (versus women) & $5.69(5.07-6.37)^{\ddagger}$ & $4.47(3.87-5.15)^{\ddagger}$ & $1.22(1.09-1.36)^{\ddagger}$ & $1.18(1.01-1.37)^{*}$ \\
\hline \multicolumn{5}{|l|}{ Body mass index six categories } \\
\hline$\leq 19.0 \mathrm{~kg} / \mathrm{m}^{2}$ & $0.73(0.63-0.86)^{\ddagger}$ & $1.22(1.02-1.47)^{*}$ & $0.98(0.79-1.20)$ & $1.23(0.99-1.53)$ \\
\hline $19.1-21.0 \mathrm{~kg} / \mathrm{m}^{2}$ & $0.80(0.71-0.89)^{\ddagger}$ & $1.06(0.93-1.20)$ & $0.81(0.69-0.96)^{*}$ & $0.94(0.80-1.11)$ \\
\hline $21.1-22.9 \mathrm{~kg} / \mathrm{m}^{2}$ & 1 & 1 & 1 & 1 \\
\hline $23.0-24.9 \mathrm{~kg} / \mathrm{m}^{2}$ & $1.37(1.25-1.50)^{\ddagger}$ & $1.05(0.94-1.17)$ & $1.05(0.91-1.21)$ & $0.89(0.77-1.03)$ \\
\hline $25.0-26.9 \mathrm{~kg} / \mathrm{m}^{2}$ & $1.46(1.32-1.62)^{\ddagger}$ & $1.06(0.95-1.19)$ & $1.10(0.94-1.28)$ & $0.89(0.76-1.05)$ \\
\hline$\geq 27.0 \mathrm{~kg} / \mathrm{m}^{2}$ & $1.00(0.90-1.11)$ & $0.95(0.84-1.08)$ & $0.88(0.74-1.03)$ & $0.88(0.74-1.05)$ \\
\hline \multicolumn{5}{|l|}{ White blood cell } \\
\hline$<25 \%$ tile & 1 & 1 & 1 & 1 \\
\hline $25-49.9 \%$ tile & $1.29(1.17-1.42)^{\ddagger}$ & $1.08(0.96-1.21)$ & $1.15(1.00-1.33)$ & $1.10(0.95-1.28)$ \\
\hline $50-75 \%$ tile & $1.38(1.25-1.52)^{\ddagger}$ & $1.07(0.95-1.19)$ & $1.13(0.98-1.31)$ & $1.07(0.92-1.24)$ \\
\hline$>75 \%$ tile $\left(\geq 88.9 \times 10^{2} / \mu \mathrm{L}\right)$ & $1.67(1.52-1.83)^{\ddagger}$ & $1.15(1.03-1.29)^{*}$ & $1.18(1.02-1.36)^{*}$ & $1.08(0.92-1.26)$ \\
\hline Past history of cardiovascular disease $\mathrm{e}^{\mathrm{a}, \mathrm{b}}$ & $2.08(1.70-2.55)^{\ddagger}$ & $1.08(0.85-1.36)$ & $1.91(1.40-2.58)^{\ddagger}$ & $1.15(0.83-1.58)$ \\
\hline \multicolumn{5}{|l|}{ Complication of } \\
\hline Hypertension $^{\mathrm{b}}$ & $3.14(2.85-3.45)^{\ddagger}$ & $1.00(0.90-1.11)$ & $2.46(2.15-2.81)^{\ddagger}$ & $1.07(0.92-1.23)$ \\
\hline Dyslipidemia $^{\mathrm{b}}$ & $1.27(1.10-1.46)^{\dagger}$ & $0.81(0.70-0.95)^{\dagger}$ & $1.51(1.24-1.84)^{\ddagger}$ & $1.00(0.82-1.23)$ \\
\hline Diabetes $^{\mathrm{b}}$ & $3.71(3.27-4.21)^{\ddagger}$ & $1.53(1.32-1.76)^{\ddagger}$ & $3.06(2.54-3.68)^{\ddagger}$ & $1.56(1.28-1.90)^{\ddagger}$ \\
\hline \multicolumn{5}{|l|}{ Tinnitus } \\
\hline Present ${ }^{\mathrm{b}}$ & $4.51(3.99-5.09)^{\ddagger}$ & $3.13(2.71-3.62)^{\ddagger}$ & $3.13(2.60-3.77)^{\ddagger}$ & $2.03(1.67-2.47)^{\ddagger}$ \\
\hline \multicolumn{5}{|l|}{ Smoking } \\
\hline No smoker & 1 & 1 & 1 & 1 \\
\hline Past smoker & $1.89(1.71-2.09)^{\ddagger}$ & $0.98(0.87-1.11)$ & $1.19(1.02-1.39)$ & $0.96(0.81-1.13)$ \\
\hline Current smoker & $2.04(1.90-2.18)^{\ddagger}$ & $1.29(1.18-1.41)^{\ddagger}$ & $1.15(1.04-1.28)^{\dagger}$ & $1.08(0.95-1.22)$ \\
\hline \multicolumn{5}{|l|}{ Alcohol consumption } \\
\hline No drinker & 1 & 1 & 1 & 1 \\
\hline Occasional drinker & $0.54(0.48-0.60)^{\ddagger}$ & $0.95(0.84-1.07)$ & $0.49(0.42-0.56)^{\ddagger}$ & $0.87(0.74-1.01)$ \\
\hline 1 3/week drinker & $0.77(0.69-0.86)^{\ddagger}$ & $0.85(0.75-0.96)^{\dagger}$ & $0.62(0.52-0.73)^{\ddagger}$ & $0.85(0.72-1.01)$ \\
\hline 4 6/week drinker & $1.31(1.18-1.46)^{\ddagger}$ & $0.93(0.83-1.06)$ & $0.82(0.70-0.97)^{*}$ & $0.82(0.69-0.98)^{*}$ \\
\hline Daily drinker & $2.40(2.21-2.62)^{\ddagger}$ & $1.17(1.05-1.30)^{\dagger}$ & $1.37(1.20-1.55)^{\ddagger}$ & $1.04(0.90-1.20)$ \\
\hline \multicolumn{5}{|l|}{ Exercise } \\
\hline$\geq 2 /$ week exerciser & 1 & 1 & 1 & 1 \\
\hline 1/week exerciser & $0.94(0.84-1.05)$ & $0.99(0.87-1.13)$ & $0.83(0.71-0.99)^{*}$ & $0.93(0.78-1.10)$ \\
\hline Occasional exerciser & $0.88(0.78-0.99)^{*}$ & $1.12(0.97-1.29)$ & $0.72(0.59-0.87)^{\ddagger}$ & $0.99(0.81-1.21)$ \\
\hline No exerciser & $1.13(1.03-1.23)^{*}$ & $1.18(1.06-1.31)^{\dagger}$ & $1.10(0.96-1.25)$ & $1.18(1.02-1.36)^{*}$ \\
\hline \multicolumn{5}{|l|}{ Work duration } \\
\hline$\leq 6 \mathrm{~h}$ & 1 & 1 & 1 & 1 \\
\hline $7 \mathrm{~h}$ & $1.58(1.34-1.85)^{\ddagger}$ & $1.05(0.86-1.29)$ & $0.89(0.73-1.10)$ & $0.90(0.72-1.11)$ \\
\hline $8 \mathrm{~h}$ & $1.27(1.12-1.45)^{\ddagger}$ & $1.00(0.85-1.18)$ & $0.61(0.52-0.70)^{\ddagger}$ & $0.85(0.71-1.01)$ \\
\hline $9 \mathrm{~h}$ & $0.96(0.83-1.11)$ & $0.87(0.72-1.06)$ & $0.45(0.37-0.55)^{\ddagger}$ & $0.76(0.61-0.95)^{*}$ \\
\hline $10 \mathrm{~h}$ & $0.93(0.79-1.08)$ & $0.92(0.76-1.11)$ & $0.40(0.32-0.49)^{\ddagger}$ & $0.71(0.56-0.90)^{\dagger}$ \\
\hline$\geq 11 \mathrm{~h}$ & $0.70(0.60-0.82)^{\ddagger}$ & $0.87(0.72-1.06)$ & $0.29(0.24-0.36)^{\ddagger}$ & $0.62(0.48-0.79)^{\ddagger}$ \\
\hline
\end{tabular}

${ }^{*} P<0.05,{ }^{\dagger} P<0.01$, and ${ }^{\ddagger} P<0.001$.

${ }^{a}$ Cardiovascular disease including heart disease and stroke.

${ }^{\mathrm{b}}$ Present versus absent.

Confounding factors in multivariate adjustments include those listed in Model 2a of Table 2.

Numbers in exercise express the times of exercise ( $>30$ min per session). 
TABLE 4: Baseline clinical characteristics of subjects and prevalence of longer sleep duration eight years later in the longitudinal study.

\begin{tabular}{|c|c|c|c|c|c|}
\hline Categories by sleep duration & Total & $\leq 5 \mathrm{~h}$ & $6 \mathrm{~h}$ & $7 \mathrm{~h}$ & $P$ values \\
\hline$N,(\%$ of total $)$ & 6,774 & $450(10.5)$ & $3,063(46.6)$ & $3,261(31.4)$ & - \\
\hline Age (years) & $41.6 \pm 9.0$ & $40.2 \pm 9.5$ & $41.2 \pm 9.1$ & $42.1 \pm 8.8$ & $<0.0001$ \\
\hline Men, $n(\%)$ & $4,639(68.5)$ & $268(59.6)$ & $1,959(64.0)$ & $2,412(74.0)$ & $<0.0001$ \\
\hline $\operatorname{BMI}\left(\mathrm{kg} / \mathrm{m}^{2}\right)$ & $23.2 \pm 3.3$ & $23.3 \pm 3.6$ & $23.3 \pm 3.4$ & $23.2 \pm 3.1$ & 0.67 \\
\hline Systolic blood pressure (mmHg) & $123 \pm 16.0$ & $122 \pm 15.7$ & $123 \pm 16.0$ & $124 \pm 16.0$ & $<0.0001$ \\
\hline Diastolic blood pressure $(\mathrm{mmHg})$ & $74 \pm 12.2$ & $72 \pm 12.2$ & $74 \pm 12.2$ & $75 \pm 12.1$ & $<0.0001$ \\
\hline HbAlc (\%, NGSP) & $5.4 \pm 0.6$ & $5.4 \pm 0.8$ & $5.4 \pm 0.6$ & $5.4 \pm 0.6$ & 0.39 \\
\hline White blood cell $\left(\times 10^{2} / \mu \mathrm{L}\right)$ & $65.0 \pm 17.4$ & $64.0 \pm 16.4$ & $64.9 \pm 17.7$ & $65.3 \pm 17.1$ & 0.32 \\
\hline Past history of CVD, $n(\%)$ & $84(1.2)$ & $10(2.2)$ & $36(1.2)$ & $38(1.2)$ & 0.15 \\
\hline \multicolumn{6}{|l|}{ Medication for } \\
\hline Hypertension, $n(\%)$ & $259(3.8)$ & $13(2.9)$ & $113(3.7)$ & $133(4.1)$ & 0.41 \\
\hline Dyslipidemia, $n(\%)$ & $71(1.0)$ & $0(0.0)$ & $33(1.1)$ & $38(1.2)$ & $-^{*}$ \\
\hline Diabetes, $n(\%)$ & $66(1.0)$ & $5(1.1)$ & $32(1.0)$ & $29(0.9)$ & $-^{*}$ \\
\hline \multicolumn{6}{|l|}{ Alcohol consumption } \\
\hline No $\sim$ occasional/1 3/w/4 6/w/daily $(\%)^{*}$ & $45 / 23 / 11 / 22$ & $48 / 26 / 8 / 17$ & $48 / 23 / 11 / 18$ & $41 / 22 / 12 / 26$ & $<0.0001$ \\
\hline Current smoker, $n(\%)$ & $2,606(38.5)$ & $171(38.0)$ & $1,120(36.6)$ & $1,315(40.3)$ & 0.009 \\
\hline \multicolumn{6}{|l|}{ Having regular exercise } \\
\hline No/occasional/1/w/ $\geq 2 / \mathrm{w}(\%)^{*}$ & $50 / 13 / 18 / 20$ & $54 / 14 / 14 / 18$ & $50 / 13 / 18 / 20$ & $47 / 14 / 19 / 20$ & 0.09 \\
\hline Hearing loss at least in one ear at $4,000 \mathrm{~Hz}, n(\%)$ & $457(6.7)$ & $19(4.2)$ & $175(5.7)$ & $263(8.1)$ & $<0.0001$ \\
\hline Hearing loss at least in one ear at $1,000 \mathrm{~Hz}, n(\%)$ & $168(2.5)$ & $8(1.8)$ & $77(2.5)$ & $83(2.5)$ & 0.61 \\
\hline Work duration (hour) (available $n=6,703$ ) & $8.5 \pm 1.2$ & $8.9 \pm 1.4$ & $8.6 \pm 1.2$ & $8.4 \pm 1.1$ & $<0.0001$ \\
\hline Prevalence of longer sleep duration eight years later, $n(\%)$ & $452(6.7)$ & $11(2.4)$ & $109(3.6)$ & $332(10.2)$ & $<0.0001$ \\
\hline
\end{tabular}

The data are expressed as means \pm SD. Triglyceride is expressed as medians (interquartiles).

Individuals with longer sleep duration ( $\geq 8$ hour) at baseline were not enrolled in the longitudinal study.

* Total sum is not $100 \%$ in some cases because of decimal points.

BMI: body mass index, HDL: high-density lipoprotein, NGSP: national glycohemoglobin standardization program, and CVD: cardiovascular disease (including stroke).

TABLE 5: Relative risks for longer sleep duration according to baseline hearing loss.

\begin{tabular}{lcccc}
\hline & \multicolumn{2}{c}{ Baseline hearing loss at $4000 \mathrm{~Hz}$} & \multicolumn{2}{c}{ Baseline hearing loss at 1000 Hz } \\
& Absent & Present & Absent & Present \\
\hline Baseline & 6317 & 457 & 6606 & 168 \\
Long-time sleep in 2008 & 394 & 58 & 433 & 19 \\
\hline & & Relative risk $(95 \%$ CI $)$ & 1 & Relative risk (95\% CI) \\
\hline Model 1 & 1 & $2.19(1.63-2.93)^{\dagger}$ & 1 & $1.82(1.12-2.96)^{*}$ \\
Model 2 & 1 & $1.56(1.14-2.13)^{*}$ & $1.50(0.92-2.47)$ \\
Model 3 & 1 & $1.53(1.11-2.10)^{*}$ & 1 & $1.52(0.92-2.50)$ \\
\hline
\end{tabular}

${ }^{*} P<0.01$ and ${ }^{\dagger} P<0.001$.

Longer sleep duration at the time point of 9 years was defined as $\geq 8 \mathrm{~h}$. Hearing loss was defined as loss of hearing of $>25 \mathrm{~dB}$ in at least one ear.

The number of subjects in each group is the same as that in Table 3.

Model 1: unadjusted.

Model 2: adjusted for age, sex, smoking, alcohol consumption, and regular exercise.

Model 3: Model 2 plus baseline medications for hypertension, dyslipidemia, and diabetes; baseline past history of cardiovascular disease; and baseline body mass index and white blood cell count (total available $n=6250$ ).

neutrophil-lymphocyte ratio, white blood cell count, and C-reactive protein may be associated with hearing loss of diabetic patients. Taken together, although noise-induced hearing loss commonly begins at frequency of $4000 \mathrm{~Hz}$ [3537], our results demonstrates that some cardiovascular risk factors might aggravate the pathophysiology of such noiseinduced hearing loss. Then, long-term noise exposure and cardiovascular risk factors might provoke and aggravate a pivotal health damage of hearing loss and sequentially sleep disorder, which needs to be confirmed in further study.

\section{Limitations}

Several limitations should be mentioned. First, we assessed self-reported sleep duration but not the quality of sleep or other related factors. Nocturnal awakening, insomnia, 
nocturia, daytime napping, and difficulties with falling sleep may interfere with the observed associations [8, 63, 64]. Future studies should also include objective assessments of sleep duration, preferably made using actigraphy, because such factors may be important confounding factors. Second, we did not assess socioeconomic status in terms of education or annual income. It is possible that the site of residence, work duration, or shift work could shift the endogenous sleeping duration to an exogenously restricted sleeping duration [41, 65-67]. However, adjustment for the type or duration of work did not markedly alter the associations. Third, subclinical hearing loss was only determined using an audiometric test. Other screening methods, such as whispered voice, finger rubbing, and watch tick tests, can detect subclinical hearing loss that may not be identified with audiometric tests $[6,68]$. Finally, our results may not be applicable to other populations who have different sleep durations, socioeconomic status, morbidities, and longevities, because these are likely to affect both sleep duration and subclinical hearing loss.

\section{Conclusion}

Our results suggest that subclinical hearing loss, especially at a high frequency, was independently associated with longer sleep duration and cardiometabolic risk factors in Japanese general population. Current findings remain to be warranted in further study.

\section{Conflict of Interests}

The authors declare that they have no competing interests.

\section{Authors' Contribution}

K. Nakajima designed the overall study and confirmed the ethicality of the study; K. Suwa identified eligible subjects from the database; K. Nakajima, A. Hosobuchi, and K. Suwa analyzed the data; K. Nakajima, E. Kanda, and A. Hosobuchi reviewed the literature and discussed the results; and $\mathrm{K}$. Nakajima wrote the paper. All authors reviewed and edited the paper and approved the final version of the paper.

\section{Acknowledgment}

The authors wish to thank all of the staff of Saitama Health Promotion Corporation for their kind cooperation with this study.

\section{References}

[1] A. Howarth and G. R. Shone, "Ageing and the auditory system," Postgraduate Medical Journal, vol. 82, no. 965, pp. 166-171, 2006.

[2] X. Z. Liu and D. Yan, "Ageing and hearing loss," Journal of Pathology, vol. 211, no. 2, pp. 188-197, 2007.

[3] Q. Huang and J. Tang, "Age-related hearing loss or presbycusis," European Archives of Oto-Rhino-Laryngology, vol. 267, no. 8, pp. 1179-1191, 2010.
[4] H. S. Li-Korotky, "Age-related hearing loss: quality of care for quality of life," Gerontologist, vol. 52, no. 2, pp. 265-271, 2012.

[5] A. Ciorba, C. Bianchini, S. Pelucchi, and A. Pastore, "The impact of hearing loss on the quality of life of elderly adults," Clinical Interventions in Aging, vol. 7, pp. 159-163, 2012.

[6] V. A. Moyer and U.S. Preventive Services Task Force, "Screening for hearing loss in older adults: U.S. preventive services task force recommendation statement," Annals of Internal Medicine, vol. 157, no. 9, pp. 655-661, 2012.

[7] R. S. Hallam, "Correlates of sleep disturbance in chronic distressing tinnitus," Scandinavian Audiology, vol. 25, no. 4, pp. 263-266, 1996.

[8] R. Asplund, "Sleepiness and sleep in elderly subjects with hearing complaints," Archives of Gerontology and Geriatrics, vol. 36, no. 1, pp. 93-99, 2003.

[9] K. I. Hume, "Noise pollution: a ubiquitous unrecognized disruptor of sleep?" Sleep, vol. 34, no. 1, pp. 7-8, 2011.

[10] T. Test, A. Canfi, A. Eyal, I. Shoam-Vardi, and E. K. Sheiner, "The influence of hearing impairment on sleep quality among workers exposed to harmful noise," Sleep, vol. 34, no. 1, pp. 2530, 2011.

[11] K. Ito, R. Naito, T. Murofushi, and R. Iguchi, "Questionnaire and interview in screening for hearing impairment in adults," Acta Oto-laryngologica, vol. 559, pp. 24-28, 2007.

[12] N. Nakanishi, M. Okamoto, K. Nakamura, K. Suzuki, and K. Tatara, "Cigarette smoking and risk for hearing impairment: a longitudinal study in Japanese male office workers," Journal of Occupational and Environmental Medicine, vol. 42, no. 11, pp. 1045-1049, 2000.

[13] Y. Takata, "Hearing loss associated with smoking in male workers," Journal of UOEH, vol. 33, no. 1, pp. 35-40, 2011.

[14] V. Kakarlapudi, R. Sawyer, and H. Staecker, "The effect of diabetes on sensorineural hearing loss," Otology and Neurotology, vol. 24, no. 3, pp. 382-386, 2003.

[15] D. F. Austin, D. Konrad-Martin, S. Griest, G. P. McMillan, D. McDermott, and S. Fausti, "Diabetes-related changes in hearing," Laryngoscope, vol. 119, no. 9, pp. 1788-1796, 2009.

[16] K. E. Bainbridge, Y. J. Cheng, and C. C. Cowie, "Potential mediators of diabetes-related hearing impairment in the U.S. population: National Health and Nutrition Examination Survey 1999-2004," Diabetes Care, vol. 33, no. 4, pp. 811-816, 2010.

[17] T. Muneyuki, H. Sugawara, K. Suwa et al., "Design of the Saitama Cardiometabolic Disease and Organ Impairment Study (SCDOIS): a multidisciplinary observational epidemiological study," Open Journal of Endocrine and Metabolic Diseases, vol. 3, no. 2, pp. 144-156, 2013.

[18] Saitama Health Promotion Corporation, (Japanese), http:// www.saitama-kenkou.or.jp/.

[19] N. Tsuno, A. Besset, and K. Ritchie, "Sleep and depression," Journal of Clinical Psychiatry, vol. 66, no. 10, pp. 1254-1269, 2005.

[20] Y. Kaneita, T. Ohida, M. Uchiyama et al., "The relationship between depression and sleep disturbances: a Japanese nationwide general population survey," Journal of Clinical Psychiatry, vol. 67, no. 2, pp. 196-203, 2006.

[21] E. J. Mezick, M. Hall, and K. A. Matthews, "Are sleep and depression independent or overlapping risk factors for cardiometabolic disease?" Sleep Medicine Reviews, vol. 15, no. 1, pp. 51-63, 2011.

[22] J. S. Loredo, X. Soler, W. Bardwell, S. Ancoli-Israel, J. E. Dimsdale, and L. A. Palinkas, "Sleep health in U.S. Hispanic population,” Sleep, vol. 33, no. 7, pp. 962-967, 2010. 
[23] A. Kashiwagi, M. Kasuga, E. Araki et al., "International clinical harmonization of glycated hemoglobin in Japan: from Japan Diabetes Society to National Glycohemoglobin Standardization Program values," Journal of Diabetes Investigation, vol. 3, no. 1, pp. 39-40, 2012.

[24] C. Sabanayagam and A. Shankar, "Sleep duration and cardiovascular disease: results from the National Health Interview Survey," Sleep, vol. 33, no. 8, pp. 1037-1042, 2010.

[25] A. Shankar, S. Charumathi, and S. Kalidindi, "Sleep duration and self-rated health: the National Health Interview Survey 2008," Sleep, vol. 34, no. 9, pp. 1173-1177, 2011.

[26] WHO Expert Consultation, "Appropriate body-mass index for Asian populations and its implications for policy and intervention strategies," The Lancet, vol. 363, pp. 157-163, 2004.

[27] M. P. Weijenberg, E. J. M. Feskens, and D. Kromhout, "White blood cell count and the risk of coronary heart disease and all-cause mortality in elderly men," Arteriosclerosis, Thrombosis, and Vascular Biology, vol. 16, no. 4, pp. 499-503, 1996.

[28] H. J. Sun, Y. P. Jung, H. Kim, Y. L. Tae, and J. M. Samet, "White blood cell count and risk for all-cause, cardiovascular, and cancer mortality in a cohort of Koreans," The American Journal of Epidemiology, vol. 162, no. 11, pp. 1062-1069, 2005.

[29] E. Jia, Z. Yang, B. Yuan et al., "Relationship between leukocyte count and angiographical characteristics of coronary atherosclerosis," Acta Pharmacologica Sinica, vol. 26, no. 9, pp. 10571062, 2005.

[30] E. Kiesswetter, A. Seeber, R. Nat, K. Golka, and B. Sietmann, "Solvent exposure, shiftwork, and sleep," International Journal of Occupational and Environmental Health, vol. 3, supplement 2, pp. S61-S66, 1997.

[31] M. Viaene, G. Vermeir, and L. Godderis, "Sleep disturbances and occupational exposure to solvents," Sleep Medicine Reviews, vol. 13, no. 3, pp. 235-243, 2009.

[32] C. Zocchetti, D. Consonni, and P. A. Bertazzi, "Relationship between prevalence rate ratios and odds ratios in crosssectional studies," International Journal of Epidemiology, vol. 26, no. 1, pp. 220-223, 1997.

[33] K. L. Knutson, "Sleep duration and cardiometabolic risk: a review of the epidemiologic evidence," Best Practice and Research: Clinical Endocrinology and Metabolism, vol. 24, no. 5, pp. 731-743, 2010.

[34] C. Chao, J. Wu, Y. Yang et al., "Sleep duration is a potential risk factor for newly diagnosed type 2 diabetes mellitus," Metabolism: Clinical and Experimental, vol. 60, no. 6, pp. 799-804, 2011.

[35] O. Hong, "Hearing loss among operating engineers in American construction industry," International Archives of Occupational and Environmental Health, vol. 78, no. 7, pp. 565-574, 2005.

[36] B. Bergström and B. Nyström, "Development of hearing loss during long-term exposure to occupational noise. A 20-year follow-up study," Scandinavian Audiology, vol. 15, pp. 227-234, 1986.

[37] M. Mostaghaci, S. J. Mirmohammadi, A. H. Mehrparvar, M. Bahaloo, A. Mollasadeghi, and M. H. Davari, "Effect of workplace noise on hearing ability in tile and ceramic industry workers in Iran: a 2-year follow-up study," The Scientific World Journal, vol. 2013, Article ID 923731, 7 pages, 2013.

[38] C. J. Williams, F. B. Hu, S. R. Patel, and C. S. Mantzoros, "Sleep duration and snoring in relation to biomarkers of cardiovascular disease risk among women with type 2 diabetes," Diabetes Care, vol. 30, no. 5, pp. 1233-1240, 2007.
[39] M. I. Wallhagen, W. J. Strawbridge, and S. J. Shema, “The relationship between hearing impairment and cognitive function: a 5-year longitudinal study," Research in Gerontological Nursing, vol. 1, no. 2, pp. 80-86, 2008.

[40] F. R. Lin, L. Ferrucci, E. J. Metter, Y. An, A. B. Zonderman, and S. M. Resnick, "Hearing loss and cognition in the Baltimore Longitudinal Study of Aging," Neuropsychology, vol. 25, no. 6, pp. 763-770, 2011.

[41] L. Xu, C. Q. Jiang, T. H. Lam et al., "Short or long sleep duration is associated with memory impairment in older chinese: the Guangzhou Biobank Cohort Study," Sleep, vol. 34, no. 5, pp. 575580, 2011.

[42] F. R. Lin, K. Yaffe, J. Xia et al., "Hearing loss and cognitive decline in older adults," JAMA Internal Medicine, vol. 173, no. 4, pp. 293-299, 2013.

[43] E. I. Most, S. Aboudan, P. Scheltens, and E. J. van Someren, "Discrepancy between subjective and objective sleep disturbances in early- and moderate-stage Alzheimer disease," The American Journal of Geriatric Psychiatry, vol. 20, no. 6, pp. 460-467, 2012.

[44] D. R. Mazzotti, C. Guindalini, A. L. Sosa, C. P. Ferri, and S. Tufik, "Prevalence and correlates for sleep complaints in older adults in low and middle income countries: a 10/66 Dementia Research Group study," Sleep Medicine, vol. 13, no. 6, pp. 697702, 2012.

[45] Y. S. Ju, J. S. McLeland, C. D. Toedebusch et al., "Sleep quality and preclinical Alzheimer disease," JAMA Neurology, vol. 70, no. 5, pp. 587-593, 2013.

[46] B. Fruhstorfer, M. G. Pritsch, and H. Fruhstorfer, "Effects of daytime noise load on the sleep-wake cycle and endocrine patterns in man: I. 24 hours neurophysiological data," International Journal of Neuroscience, vol. 39, no. 3-4, pp. 197-209, 1988.

[47] F. Abad-Alegría and M. Gutiérrez, "Characteristics of sleep in deafness," Revue Neurologique, vol. 26, no. 154, pp. 959-961, 1998.

[48] A. L. Rios and G. Alves da Silva, "Sleep quality in noise exposed Brazilian workers," Noise and Health, vol. 7, no. 29, pp. 1-6, 2005.

[49] P. A. Wackym and F. H. Linthicum Jr., "Diabetes mellitus and hearing loss: clinical and histopathologic relationships," The American Journal of Otology, vol. 7, no. 3, pp. 176-182, 1986.

[50] T. L. Smith, E. Raynor, J. Prazma, J. E. Buenting, and H. C. Pillsbury, "Insulin-dependent diabetic microangiopathy in the inner ear," Laryngoscope, vol. 105, no. 3 I, pp. 236-240, 1995.

[51] Z. Shemesh, J. Attias, M. Ornan, N. Shapira, and A. Shahar, "Vitamin B12 deficiency in patients with chronic-tinnitus and noise-induced hearing loss," American Journal of Otolaryngology_Head and Neck Medicine and Surgery, vol. 14, no. 2, pp. 94-99, 1993.

[52] D. K. Houston, M. A. Johnson, R. J. Nozza et al., "Agerelated hearing loss, vitamin B-12, and folate in elderly women," American Journal of Clinical Nutrition, vol. 69, no. 3, pp. 564$571,1999$.

[53] J. Shargorodsky, S. G. Curhan, R. Eavey, and G. C. Curhan, "A prospective study of vitamin intake and the risk of hearing loss in men," Otolaryngology-Head and Neck Surgery, vol. 142, no. 2, pp. 231-236, 2010.

[54] A. O. Lasisi, F. A. Fehintola, and O. B. Yusuf, "Age-related hearing loss, vitamin B12, and folate in the elderly," OtolaryngologyHead and Neck Surgery, vol. 143, no. 6, pp. 826-830, 2010.

[55] B. Gopinath, V. M. Flood, C. M. McMahon et al., "Dietary antioxidant intake is associated with the prevalence but not incidence of age-related hearing loss," Journal of Nutrition, Health and Aging, vol. 15, no. 10, pp. 896-900, 2011. 
[56] S. H. Jee, J. W. Sull, J. Park, S. Y. Lee, H. Ohrr, and E. Guallar, "Body-mass index and mortality in Korean men and women," The New England Journal of Medicine, vol. 355, no. 8, pp. 779787, 2006.

[57] A. B. de Gonzalez, P. Hartge, J. R. Cerhan et al., "Body-mass index and mortality among 1.46 million white adults," The New England Journal of Medicine, vol. 363, no. 23, pp. 2211-2219, 2010.

[58] W. Zheng, D. F. McLerran, B. Rolland et al., "Association between body-mass index and risk of death in more than 1 million Asians," The New England Journal of Medicine, vol. 364, no. 8, pp. 719-729, 2011.

[59] J. Rehm, C. Mathers, S. Popova, M. Thavorncharoensap, Y. Teerawattananon, and J. Patra, "Global burden of disease and injury and economic cost attributable to alcohol use and alcohol-use disorders," The Lancet, vol. 373, no. 9682, pp. 2223-2233, 2009.

[60] P. E. Ronksley, S. E. Brien, B. J. Turner, K. J. Mukamal, and W. A. Ghali, "Association of alcohol consumption with selected cardiovascular disease outcomes: a systematic review and metaanalysis," BMJ, vol. 342, article d671, 2011.

[61] H. Iso, "Lifestyle and cardiovascular disease in Japan," Journal of Atherosclerosis and Thrombosis, vol. 18, no. 2, pp. 83-88, 2011.

[62] R. Gupta and P. Deedwania, "Interventions for cardiovascular disease prevention," Cardiology Clinics, vol. 29, no. 1, pp. 15-34, 2011.

[63] Y. Udo, M. Nakao, H. Honjo, O. Ukimura, H. Kitakoji, and T. Miki, "Sleep duration is an independent factor in nocturia: analysis of bladder diaries," BJU International, vol. 104, no. 1, pp. 75-79, 2009.

[64] J. Cohen-Mansfield and R. Perach, "Sleep duration, nap habits, and mortality in older persons," Sleep, vol. 35, no. 7, pp. 10031009, 2012.

[65] S. Y. Ryu, K. S. Kim, and M. A. Han, "Factors associated with sleep duration in Korean adults: Results of a 2008 community health survey in Gwangju Metropolitan City, Korea," Journal of Korean Medical Science, vol. 26, no. 9, pp. 1124-1131, 2011.

[66] K. A. Ertel, L. F. Berkman, and O. M. Buxton, "Socioeconomic status, occupational characteristics, and sleep duration in African/Caribbean immigrants and US white health care workers," Sleep, vol. 34, no. 4, pp. 509-518, 2011.

[67] T. Lallukka, L. Sares-Jäske, E. Kronholm et al., "Sociodemographic and socioeconomic differences in sleep duration and insomnia-related symptoms in Finnish adults," BMC Public Health, vol. 12, no. 1, article 565, 2012.

[68] R. Chou, T. Dana, C. Bougatsos, C. Fleming, and T. Beil, "Screening adults aged 50 years or older for hearing loss: a review of the evidence for the U.S. preventive services task force," Annals of Internal Medicine, vol. 154, no. 5, pp. 347-355, 2011. 


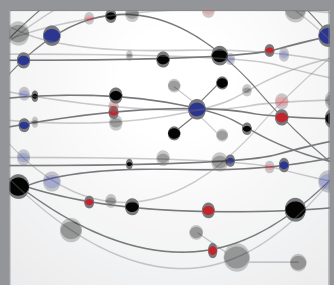

The Scientific World Journal
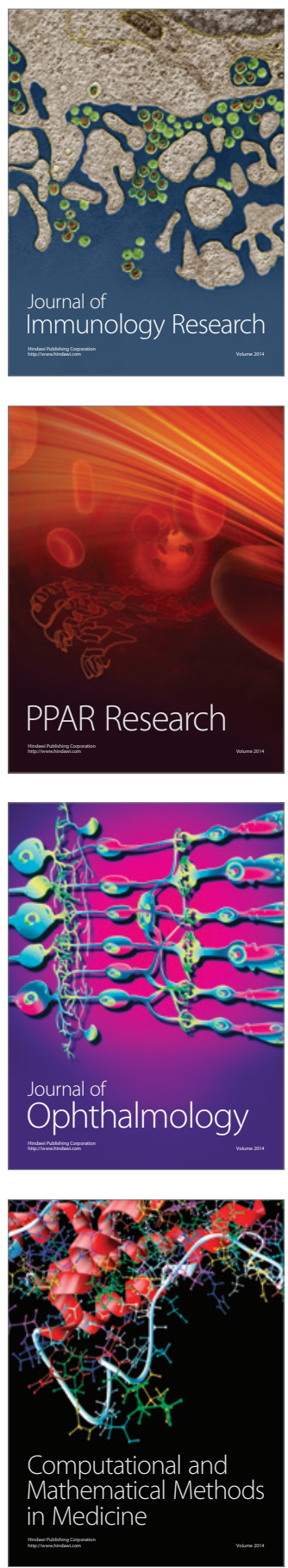

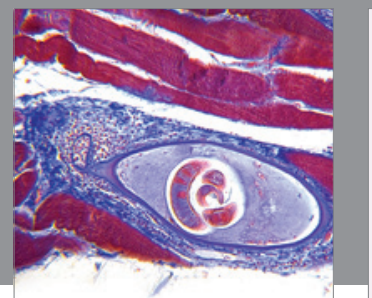

Gastroenterology

Research and Practice
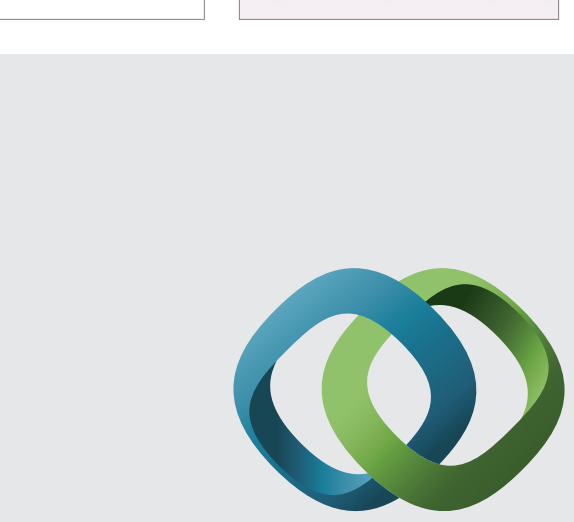

\section{Hindawi}

Submit your manuscripts at

http://www.hindawi.com
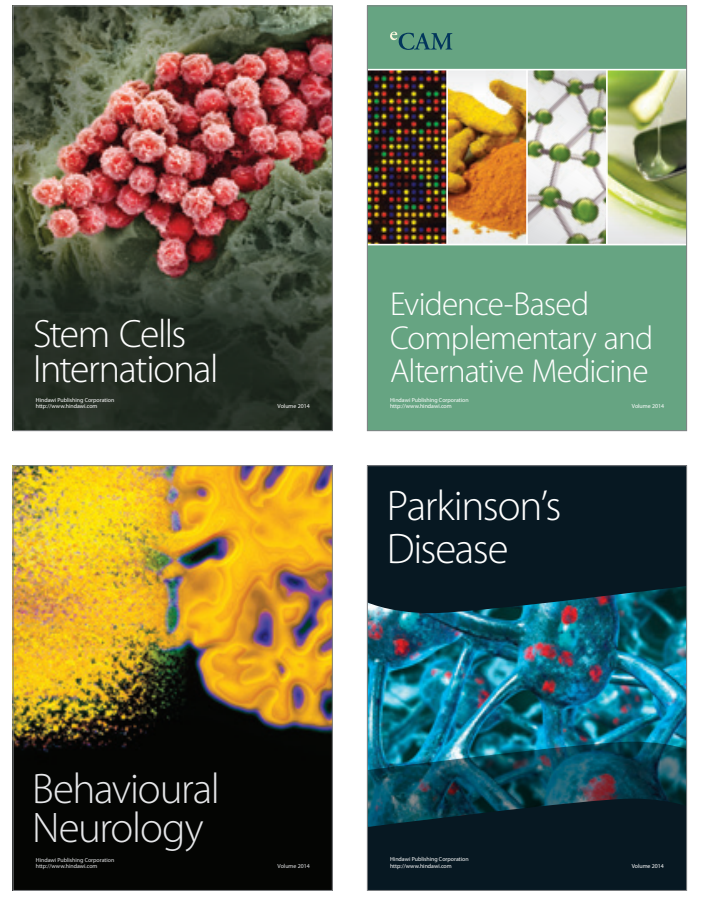
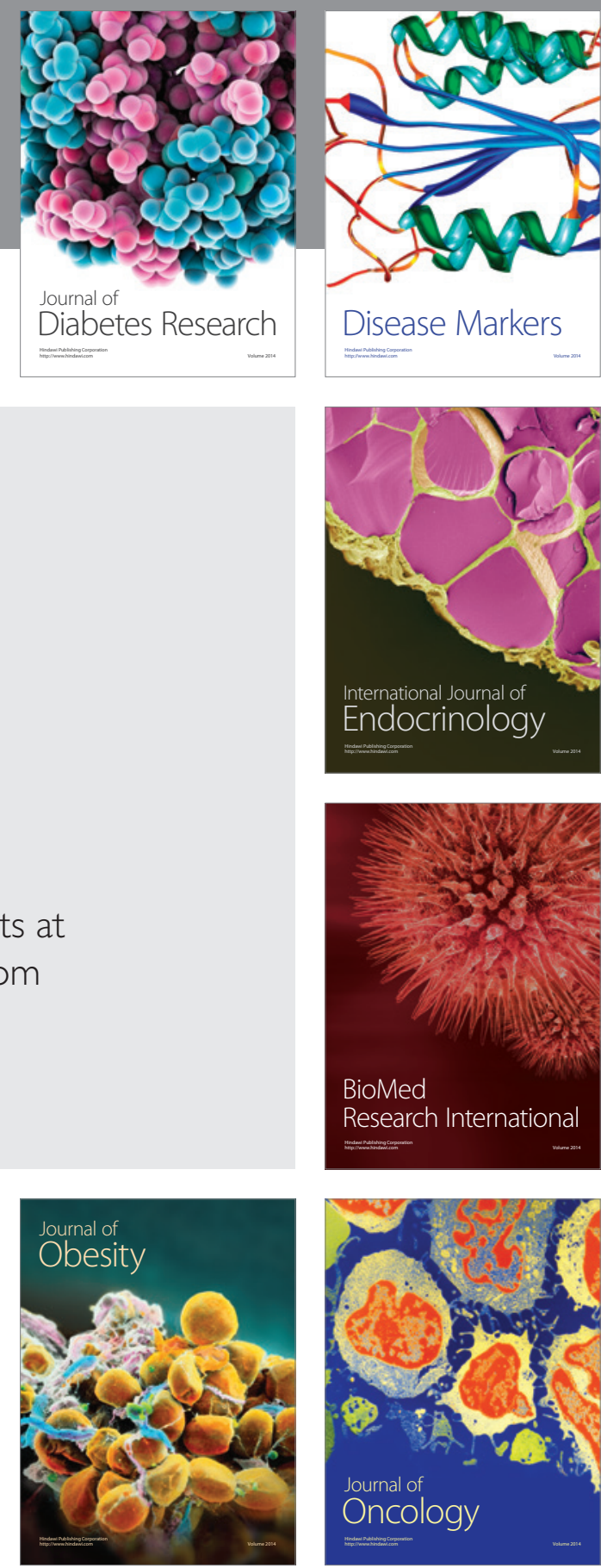

Disease Markers
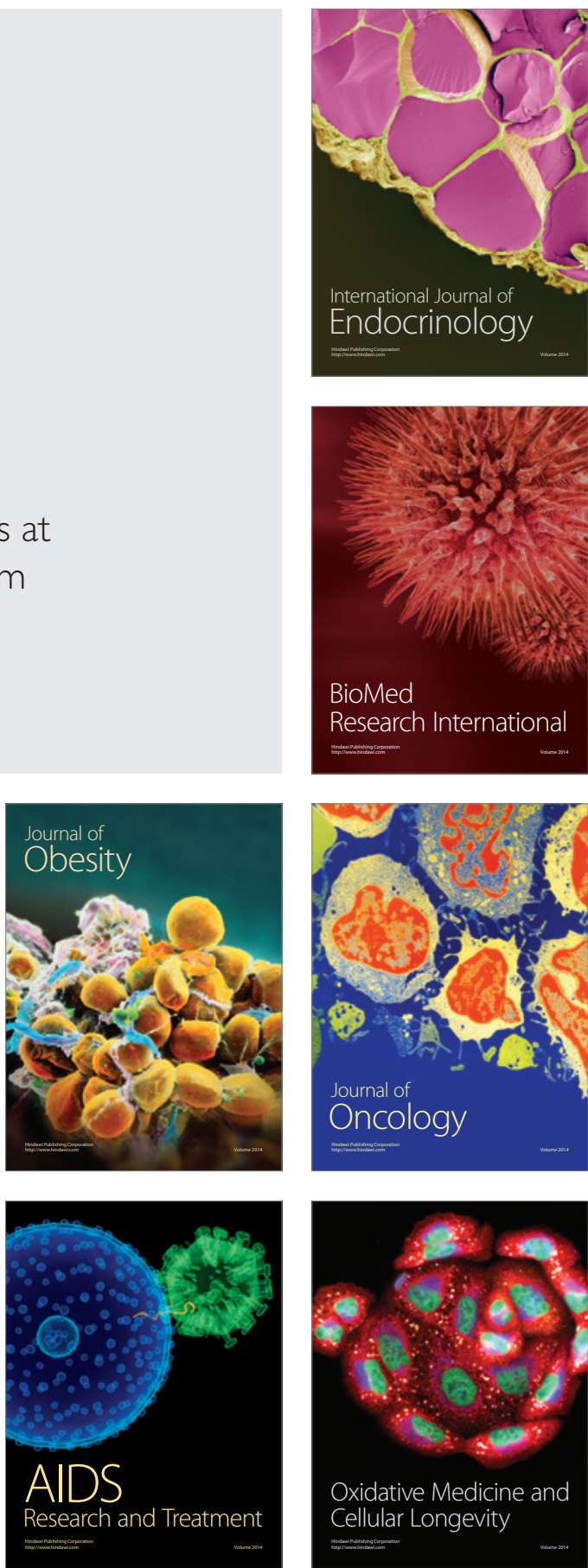